\title{
A Study on Rigorous Combination of GNSS and VLBI Observations
}

\section{Other Conference Item}

\section{Author(s):}

Herrera Pinzón, Iván D.; Rothacher, Markus

Publication date:

2021

Permanent link:

https://doi.org/10.3929/ethz-b-000528214

\section{Rights / license:}

Creative Commons Attribution 4.0 International

Originally published in:

EGUsphere 
EGU2020-9193

https://doi.org/10.5194/egusphere-egu2020-9193

EGU General Assembly 2020

(c) Author(s) 2022. This work is distributed under

the Creative Commons Attribution 4.0 License.

\section{A Study on Rigorous Combination of GNSS and VLBI Observations}

Iván Darío Herrera Pinzón and Markus Rothacher

ETH Zurich, Geodesy and Photogrammetry, Mathematical and Physical Geodesy, Zurich, Switzerland

(ivan.herrera@geod.baug.ethz.ch)

The ITRF is realized through the combination of the individual solutions (station coordinates and velocities) of the four space geodetic techniques. This combination features two main aspects: 1) precise local ties, to establish the link among techniques, and 2) full variance-covariance information of each solution, to account for the accuracy of each technique. Although this approach strives to obtain accurate geodetic products, this combination is not entirely "rigorous", especially when it comes to the Earth Orientation Parameters (EOPs). In the current realization of the ITRF only polar motion (x-pole and y-pole) are combined, whereas UT1-UTC and nutation offsets and rates are taken from the solution of a single technique (VLBI). Furthermore, parameters such as troposphere delays and clock offsets are not part of the combination strategy. Thus, a rigorous estimation of the ITRF, with consistent EOPs and with appropriate tropospheric and clock ties, is still a challenge to be met.

To achieve a rigorous combination, all parameter types common to more than one space geodetic observation technique should be combined including their full variance-covariance information as well as the corresponding ties. In particular, as both, GNSS and geodetic VLBI, are based on microwave frequencies, their physical models and their parameter types are closely related. These common parameters are the site coordinates and velocities, troposphere estimates, EOPs and (possibly) clock estimates. Thus, using the data from the CONT17 campaign as a case study, we discuss the processing scheme, the challenges and initial results of a rigorous combination of VLBI and GNSS observations, in order to estimate and densify EOPs, particularly diurnal and subdiurnal variations for polar motion and UT1-UTC, and to realize an inter-technique tropospheric tie, thus remedying the deficiencies mentioned above. The results obtained constitute an important step towards the realization of a rigorous ITRF solution that is able to improve the accuracy and consistency of all geodetic products. 